\begin{tabular}{|c|c|c|}
\hline & Int.J.Curr.Microbiol.App.Sci (2016) 5(12): $475-485$ & \multirow{4}{*}{ 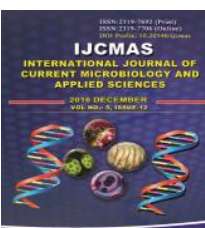 } \\
\hline & International Journal of Current Microbiology and Applied Sciences & \\
\hline & ISSN: 2319-7706 Volume 5 Number 12 (2016) pp. 475-485 & \\
\hline EXCELLENT & & \\
\hline PUBLISHERS & & www.jicmas.com \\
\hline
\end{tabular}

Original Research Article

http://dx.doi.org/10.20546/ijcmas.2016.512.051

\title{
Incidence of Aerobic Bacterial Infection in Postoperative Closed and Open Fracture Wounds at Tertiary Care Hospital in Western Rajasthan, India
}

\author{
Vinod Maurya ${ }^{1 *}$, Prabhat Kiran Khatri ${ }^{1}$, R.S. Parihar ${ }^{1}$, Kishor Raichandani ${ }^{2}$, \\ Saroj Meena ${ }^{1}$, Archana Bora ${ }^{1}$, Laxmi Rathore ${ }^{1}$, Shivani Khullar ${ }^{1}$, \\ K.L. Seervi ${ }^{1}$ and Kamlesh Kumar ${ }^{2}$ \\ ${ }^{1}$ Department of Microbiology, Dr. S. N. Medical College, Jodhpur, Rajasthan \\ ${ }^{2}$ Department of Orthopedics, Dr. S. N. Medical College, Jodhpur, Rajasthan \\ *Corresponding author:
}

Keywords

Post-Operative Infection, Orthopedic Fractures, Closed Fracture, Open Fracture, Antibiotic Sensitivity, Western Rajasthan.

\section{Article Info}

Accepted:

18 November 2016

Available Online:

10 December 2016

\section{A B S T R A C T}

Infection is still noted to be one of the major complications in the treatment of fractures. Infections are associated with prolonged hospital stay, leading to higher treatment cost, morbidity and mortality, particularly when the infecting agents are multidrug resistant. To compare incidence of infective agents and their resistance pattern between post-operative closed and open fracture wounds. In this particular study 125 patients of all age group were enrolled with exclusion of patients with history of diabetes mellitus, chronic steroid therapy, chemotherapy and HIV positive patients. Patients were divided into closed fracture and open fracture patients. A total of 120 isolates were obtained from 110 patients. 15 patients were cultured sterile. Organisms obtained were Enterobacter spp. (19.17\%), Klebsiella spp. (15.83\%), Staphylococcus aureus (12.5\%), Coagulase negative Staphylococcus spp. (11.67\%), E. coli (10.83\%), Pseudomonas (10.83\%), Acinetobacter spp. (7.50\%), Citrobacter spp. (5.0\%), Burkholderia cepacia complex (2.5\%), Aeromonas hydrophila (2.5\%), Proteus mirabilis $(0.83 \%)$ and Aerococcus viridans $(0.83 \%)$. $100 \%$ isolates of Staphylococcus species were sensitive against vancomycin, followed by linezolid, gentamicin, tetracycline, ciprofloxacin and azithromycin. Ampicillin, amox-clav and ceftriaxone were most ineffective drugs. Enterobacteriaceae isolates were almost totally resistant against ampicillin followed by amoxy-clav. Levofloxacin and imipenem were found most effective antibiotics. Non-enterobacteriaceae gram negative strains were multidrug resistant, ciprofloxacin, levofloxacin and imipenem were found effective in 50$63 \%$ patients. In our study there was no significant difference of antibiotic sensitivity pattern was noted between post-operative closed and open fracture wounds.

\section{Introduction}

Fracture wounds are very common in orthopedic wards. They may arise following trauma, in association with hemoglobin- opathy, post-operatively, or could be primarily of infective origin. The contamination or mere presence of 
pathogenic organism in wound without local or systemic tissue or both involvement may not result in infection in patient (Badoe et al., 1986). Wound infection could be defined as presence of pus in a lesion, as well as other general or local features of sepsis including pyrexia, pain and induration (Shija, 1976). A recent prevalence study has found that post surgical infections now termed as Surgical Site Infections (SSI)] were most common health care associated infection, accounting for $31 \%$ of all health care associated infections (HAIs) among hospitalized patients (Mangram et al., 1999).

Open fractures are more commonly associated with the infection. The treatment of open fractures along with infection has been improved in recent years. Disruption of the tissue barrier makes underlying structure prone to infection due to contact with environment (Horan et al., 1992). Infections in closed fractures are Healthcare Associated Infection (HAI) received during operative procedures of Open Reduction and Internal Fixation (ORIF). Studies have found in Open Reduction and Internal Fixation (ORIF) procedures an over-all infection rate is more as compared to closed fractures (De Bakey et al., 1946). Anatomic site and the severity of soft-tissue trauma may cause varying degree of infection and that may lead to complications with the tibia being most often affected (Fischer $e t$ al., 2000).

Knowledge of the etiological agents and their antibiotic susceptibility enables in selection of most appropriate antibiotic, therefore reducing treatment cost and duration of hospital stay. ORIF of with implants and prosthesis has now become the predominant modality of treatment of fractures in most trauma centers. This is because of the better understanding of the bio-mechanics of implants, their material and thus resulting in better functional outcome in these patients (Kirk et al., 2004). Surgical site infections remain the third most common nosocomial infection after urinary tract infections and pneumonia, and are the most common nosocomial infection in the surgical population at $38 \%$ (Anderson \& Sexton, 2007).

Besides advanced techniques, nosocomial infection also poses hurdles in treatment of patients. Discovery of superbugs in hospital settings are creating great challenge in the choice of antibiotics.

\section{Subjects and Methods}

Samples for the present study were obtained from post-operative patients who had undergone operative procedure for management of closed or open fractures. Surgical sites were considered infected according to the set of clinical criteria mentioned by CDC. The specimens were collected aseptically using sterile cotton wool swabs. Samples were obtained from surgical site from the depth of wound, without contaminating with skin commensals and immediately transported to laboratory.

\section{Inclusion criteria}

1. Closed fracture wound patients with post-operative infection.

2. Open fracture wound patients with postoperative infection.

\section{Exclusion criteria}

1. Patients with immunodeficient states like diabetes mellitus, obesity, carcinoma, HIV/AIDS patients and patients on drugs such as steroids or cytotoxics. 
2. Patients with pathological fractures.

3. Refusal to give consent for participating in the study.

\section{Patient data collection}

Structured questionnaires were used to extract data from the patients' case notes and/or the patients directly. The information included were, demographic data, existing chronic disease, immunocompromised states, smoking, occupation and any significant family history.

Identification of organisms: Bacterial isolates were identified by conventional methods and also by Vitek 2 automated system.

\section{Antimicrobial Susceptibility Testing}

Antimicrobial susceptibility pattern of isolated bacterial pathogens was performed by Kirby Bauer Disc Diffusion method (Bauer et al., 1966) and results were interpreted using criteria mentioned in the CLSI guidelines M100-S25.

Commercially available disks from Himedia were used. Gram positive isolates were tested against ampicillin $(10 \mu \mathrm{g})$, amoxy-clav $(10 \mu \mathrm{g})$, cefoxitin $(30 \mu \mathrm{g})$, ciprofloxacin $(5 \mu \mathrm{g})$, azithromycin $(30 \mu \mathrm{g})$, clindamycin $(2 \mu \mathrm{g})$, vancomycin $(10 \mu \mathrm{g})$, tetracycline $(30 \mu \mathrm{g})$, linezolid $(30 \mu \mathrm{g})$ and gentamicin $(10 \mu \mathrm{g})$. Gram negative isolates were tested against ampicillin $(10 \mu \mathrm{g})$, amoxy-clav $(10 \mu \mathrm{g})$, piperacillin $(100 \mu \mathrm{g})$, ceftriaxone $(30 \mu \mathrm{g})$, ceftazidime $(30 \mu \mathrm{g})$, cefepime $(30 \mu \mathrm{g})$, ciprofloxacin $(5 \mu \mathrm{g})$, levofloxacin $(5 \mu \mathrm{g})$, imipenem $(10 \mu \mathrm{g})$, amikacin $(30 \mu \mathrm{g})$ and gentamicin $(10 \mu \mathrm{g})$.

Quality control: Escherichia coli (ATCC25922) and Staphylococcus aureus (ATCC25923) were used as reference strains for identification and drug susceptibility testing.

\section{Results and Discussion}

In the present study 125 cases of open and closed fracture wounds were included who showed signs of post-operative infection at surgical site. The patients of both gender and different age groups were included. Duration of study was from February 2015 to January 2016.

Out of 125 cases 102 were males and 23 patients were females. Among 102 male patients 63 were having closed fracture and 39 were having open fracture. Among 23 female patients 19 were having closed fracture and 4 were having open fracture. Closed fracture cases were more $(65.6 \%)$ as compared to open fracture cases $(34.4 \%)$. Majority of cases belonged to middle age group. [Figure 1] Out of total 125 samples processed, 110 showed growth of pyogenic organisms and 15 samples were found sterile.

In this study 110 samples were culture positive. Majority of which 101 (91.81\%) had single isolate in culture, while 8 $(7.27 \%)$ had mixed growth with two bacteria and $1(0.91 \%)$ showed mixed growth of three bacteria. Among monoisolates $68(95.77 \%)$ samples were of closed fracture cases, $33(84.61 \%)$ were of open fracture cases. Cases showing mixed growth of two bacteria were three $(4.23 \%)$ among closed and five (12.82\%) among open fracture cases. One sample $(2.56 \%)$ which showed growth of three bacteria was open fracture case. Mixed bacterial growth was higher in open fracture cases.

In this study overall isolated bacteria were Enterobacter species, 23 (18.4\%) most common isolated bacteria. Second most 
common bacteria were Klebsiella spp. 19 (15.2\%). Staphylococcus aureus was 15 (12\%), CoNS were 14 (11.2\%). E. coli was 13 (10.4\%). Pseudomonas was 13 (10.4\%), Acinetobacter spp. was 9 (7.2\%), Citrobacter was 6 (4.8\%), Burkholderia cepacia complex was 3 (2.4\%) Aeromonas was also $3(2.4 \%)$, Proteus 1 (0.8\%), and Aerococcus $1(0.8 \%)$ were grown in open fractures only. [Figure 2] shows frequency of bacteria isolated from post-operative infection of closed and open fracture wounds.

Among gram positive bacteria vancomycin, linezolid, gentamycin, ampicillin, amoxclav and ceftriaxone showed similar pattern between closed and open fracture isolates. For drugs ciprofloxacin, azithromycin and clindamycin open fracture isolates were found more sensitive than resistant isolates. Among gram positive cocci one isolate of Aerococcus viridans was also detected and was found resistant to ciprofloxacin only.

In this study incidence of resistance in Enterobacteriaceae group of isolates against ampicillin was $100 \%$ in both closed and open fracture cases. For antibiotics amoxyclav and ceftriaxone incidence of resistance in open fracture cases were $100 \%$ but in closed fracture cases it was $97.06 \%$ for both. For piperacillin resistance was $85.29 \%$ and $75 \%$ in closed and open fracture cases respectively.

For cefepime and gentamicin $75 \%$ in open fracture cases and in closed fracture cases it was $79.41 \%$ and $73.53 \%$ respectively. Other antibiotics that were effective for most of the isolates were ciprofloxacin, levofloxacin, imipenem and amikacin; incidence of resistance for these was $47.06 \%, 23.53 \%, 29.41 \%$ and $50 \%$ respectively for closed fracture cases; and $42.86 \%, 28.57 \%, 28.57 \%, 57.14 \%$ for open fracture cases respectively.
In this study, gram negative nonEnterobacteriaceae group of isolates in closed fracture cases were found totally resistant for ampicillin, amoxy-clav, ceftazidime and cefepime. $85 \%$ of bacteria were resistant to gentamicin. $70 \%$ of isolates were resistant to piperacillin and amikacin. $40-50 \%$ of bacteria were resistant to imipenem levofloxacin and ciprofloxacin. In case of open wound fractures, only piperacillin, imipenem, ciprofloxacin and levofloxacin were found to be effective and incidence of resistance was $87.5 \%, 37.5 \%, 37.5 \%$ and $37.5 \%$ respectively

Antibiotic resistance pattern of gram positive isolates, enterobacteriaceae and non-enterobacteriaceae gram negative isolates are shown in detail in [Figure 3], [Figure 4], [Figure 5] respectively.

In this study methicillin resistance was detected using cefoxitin $30 \mu \mathrm{g}$ disc. $50 \%$ of Staphylococcus aureus in closed fracture isolates were positive for cefoxitin screen and $20 \%$ in open fracture isolates. Among CoNS $30 \%$ of closed fracture and $20 \%$ of open fracture isolates were found positive in cefoxitin screening. Total six isolates (40\%) were MRSA among 15 Staphylococcus isolates. Incidence of MRSA was $5 \%$ in this study.

In this study total 29 bacteria $(24.17 \%)$ out of 120 isolates were found to be ESBL producers which included five isolates of $E$. coli, three $(42.85 \%)$ in closed fractures and two isolates $(33.33 \%)$ in open fracture cases; nine isolates of Enterobacter spp., four $(40 \%)$ in closed and five $(38.46 \%)$ in open fracture cases; eight isolates Klebsiella spp., five (38.46\%) in closed and three $(50 \%)$ in open fracture cases; three isolates of Citrobacter spp., one (33.33\%) in closed and two (66.66\%) in open fracture; 
among Pseudomonas spp. five isolates, four $(40 \%)$ in closed and two $(66.66 \%)$ in open fracture cases were found to be ESBL producer. 24(38.71\%) isolates out of 62 Enterobacteriaceae isolates were ESBL producers (Table.1).

Orthopedic fractures with intact overlying skin are not exposed to external environment thus they are protected from getting infected. Sometimes these closed fractures require operative correction and may acquire healthcare associated infection. Unlike closed fractures open fractures come in contact with external environment and also suffer more tissue damage. This requires thorough cleaning of wound and operative procedures also. Thus open fractures get exposed to community as well as hospital flora. This particular study was conducted to find out difference between incidence and resistance pattern of etiological agents in closed and open fracture wounds.

The overall incidence of gram negative bacteria is more $(75 \%)$ in comparison to gram positive bacteria $(25 \%)$ in our study. Similar findings of GNB have also been reported in India by Lilani et al., 2005 (76.43\%); Alok Agrawal, 2008 (74.37\%); Rastgi et al., 2012 (62.5\%); Rajkumari et al., 2014 (73.94\%). Some authors abroad have also shown sililar results Faisham 2001 (75\%); Sule et al., 2002 (67.1\%); Wang et al., 2009 (77.8\%); Hassan et al., 2010 (77.40\%); Khairy et al., 2011 (60.86\%); Fahad Al Muhim et al., 2014 (71.96\%); Phillip Mulepo, 2014 (74\%).

Some other authors from india Jain et al., 2015 and abroad Robinson et al., 1989; Onche and Adedeji, 2004; Lee et al., 2006; Akinyoola et al., 2006; Hidron et al., 2008; Madu et al., 2010; Guo-qing Li et al., 2013; have found gram positive organisms to be more common in post-operative orthopaedic wards.

The present study findings support the theory of gradual increase in the emergence of antibiotic resistant micro-organisms in post surgical patients. Onche and Adedeji, 2004, in their study on Microbiology of post-operative wound infection in implant surgery, found gentamicin to be most effective drug followed by ofloxacin for gram negative isolates. In study done by Aloe Agrawal et al., 2008, Pseudomonas (12cases), E. coli (9 cases), Klebsiella (3 cases), Proteus (2 cases) and Streptococcus (1 case) were found to be resistant to all antibiotics. Ako-Nai et al., 2009, in their study, found $72 \%$ resistance to amoxicillin, $44 \%$ to amoxy-clav, $57 \%$ to tetracycline $23 \%$ to gentamicin, and $10 \%$ against ofloxacin. Hassan et al., 2010, in their study noted all isolates of staphylococci were susceptible to vancomycin. Resistance rates of $\geq 50 \%$ to ceftazidime and/or cefotaxime were detected especially in Klebsiella spp., Pseudomonas spp. and E. coli and Acinetobacter strains. Noticeably, susceptibility to imipenem for gram negative bacilli was $>80 \%$. Multi-resistant strains represented $48.6 \%(35 / 72)$ of the isolated gram negative strains. $57.1 \%$ and $66.7 \%$ of Pseudomonas spp. and Acinetobacter spp. isolates (19.4\% of gram negative isolates) were resistant to amikacin, ciprofloxacin and ceftazidime. Phillip Mulepo, 2014, in his study, found that the $(>80 \%)$ isolated gram negative bacteria were sensitive to amikacin, piperacillin and imipenem but resistant $(>80 \%)$ to, ampicillin, amoxy-clav, ceftriaxone, ceftazidime was noted. The isolated gram positive bacteria; Staphylococcus aureus were sensitive (>80\%) to vancomycin. 
Table.1 ESBL producing isolates

\begin{tabular}{|c|c|c|c|c|c|c|}
\hline \multirow{3}{*}{ Species } & \multicolumn{4}{|c|}{ ESBL positive } & \multirow{2}{*}{\multicolumn{2}{|c|}{ TOTAL }} \\
\hline & \multicolumn{2}{|c|}{ Closed fracture } & \multicolumn{2}{|c|}{ Open fracture } & & \\
\hline & $\mathrm{N}$ & $\%$ & $\mathrm{~N}$ & $\%$ & $\mathbf{N}$ & $\%$ \\
\hline Enterobacter spp.(23) & 4 & 40 & 5 & 38.46 & 9 & 39.13 \\
\hline Klebsiella spp.(19) & 5 & 38.46 & 3 & 50 & 8 & 26.32 \\
\hline Escherichia coli (13) & 3 & 42.85 & 2 & 33.33 & 5 & 38.46 \\
\hline Pseudomonas (13) & 4 & 40 & 1 & 33.33 & 5 & 38.46 \\
\hline Citrobacter spp.(6) & 1 & 33.33 & 2 & 66.66 & 2 & 50 \\
\hline
\end{tabular}

Fig.1 Age and gender wise distribution of patients

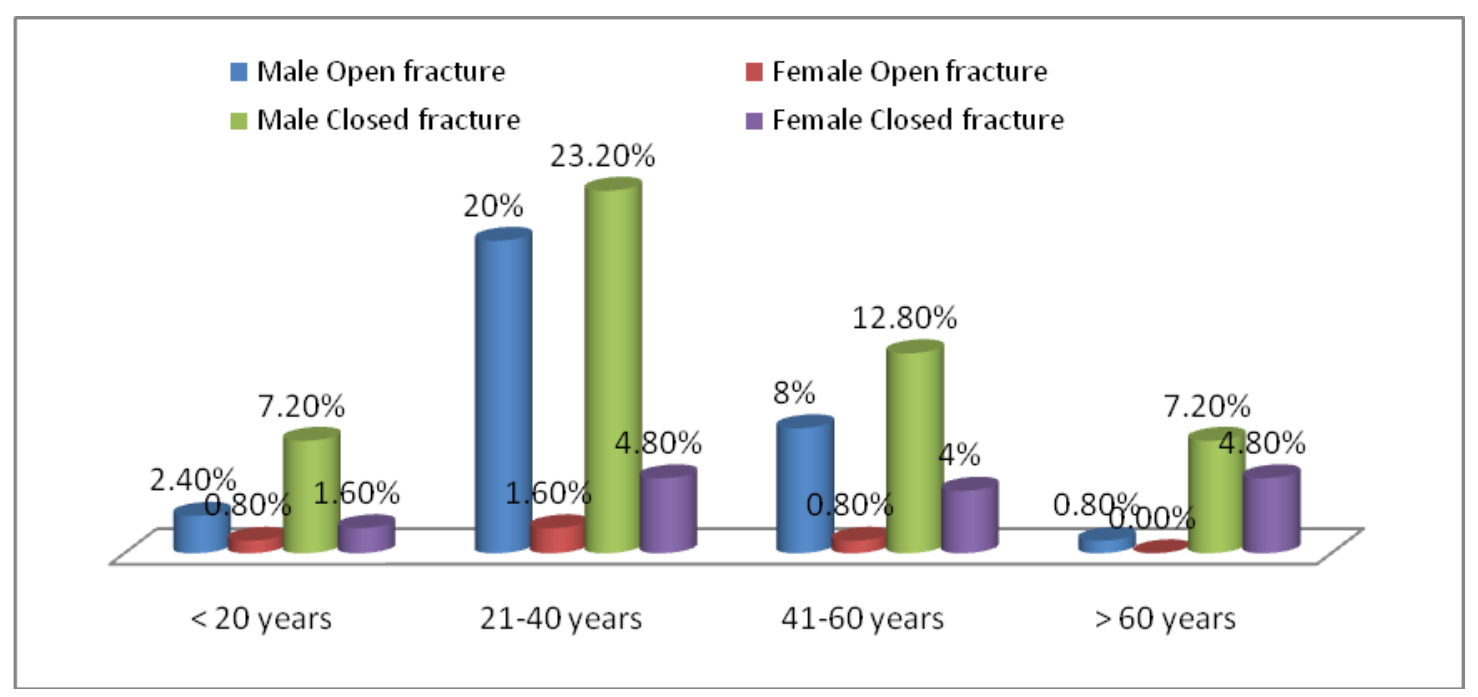

Fig.2 Frequency of organisms in closed and open fracture cases

Closed fracture Open fracture

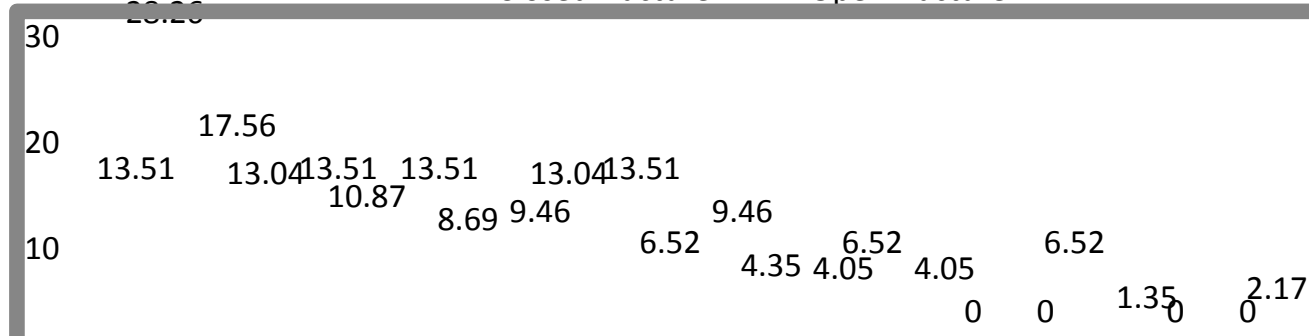

0 
Fig.3 Comparison of incidence of resistance between closed and open fracture isolates in Staphylococcus spp.

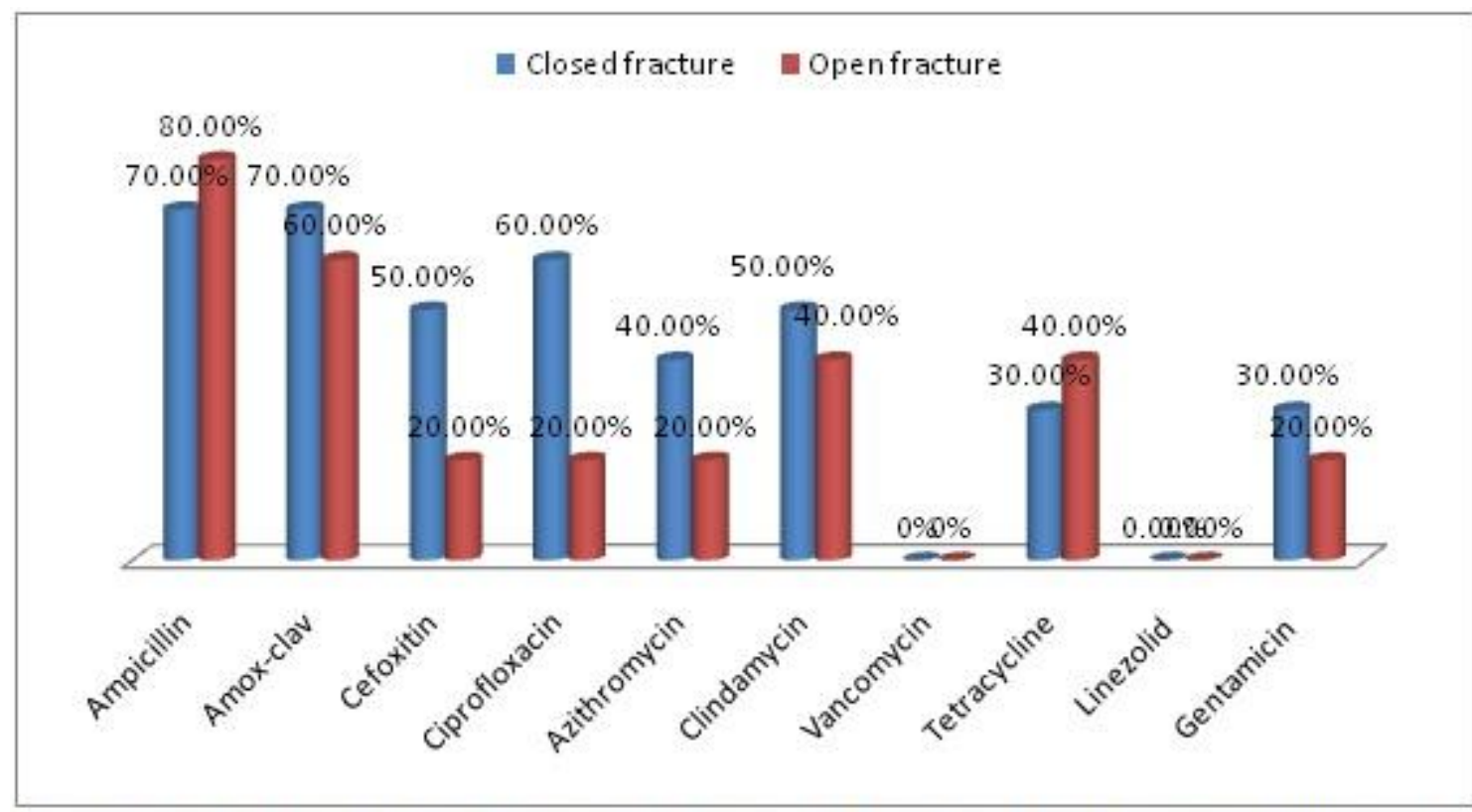

Comparison of incidence of resistance between closed and open fracture isolates in Staphvlococcus aureus

$$
\text { - Closedfracture Openfracture }
$$

$81.81 \%$
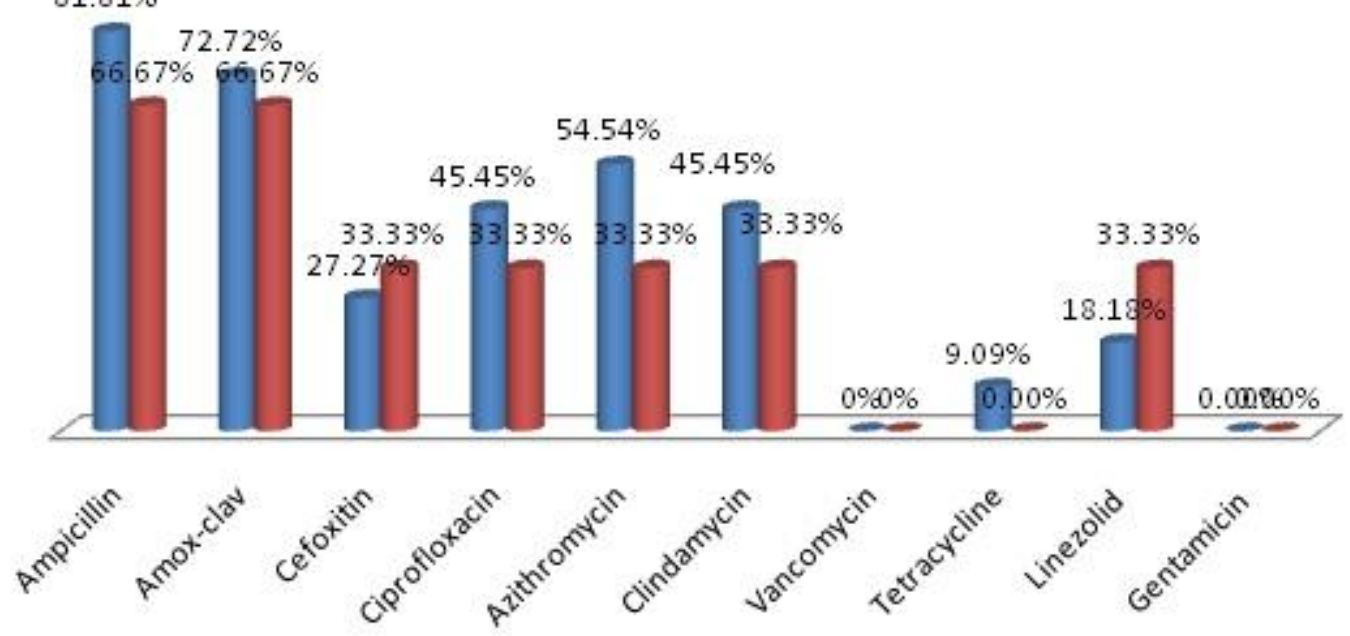

Comparison of incidence of resistance between closed and open fracture in Coagulase Negative Staphylococcus spp. 
Fig.4 Incidence of antibiotics resistance among Enterobacteriaceae group

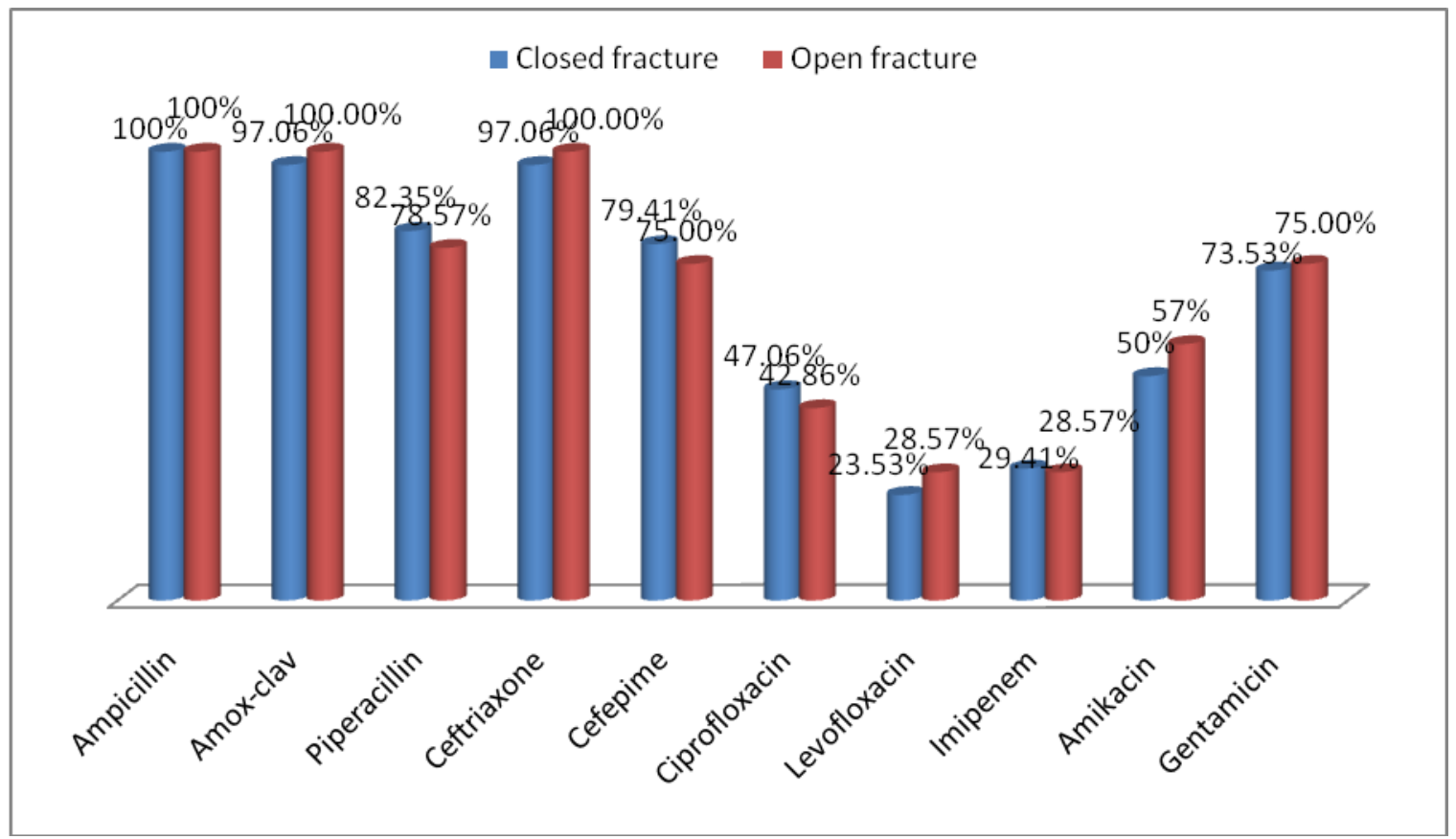

Fig.5 Incidence of antibiotics resistance among non-Enterobacteriaceae group of bacteria

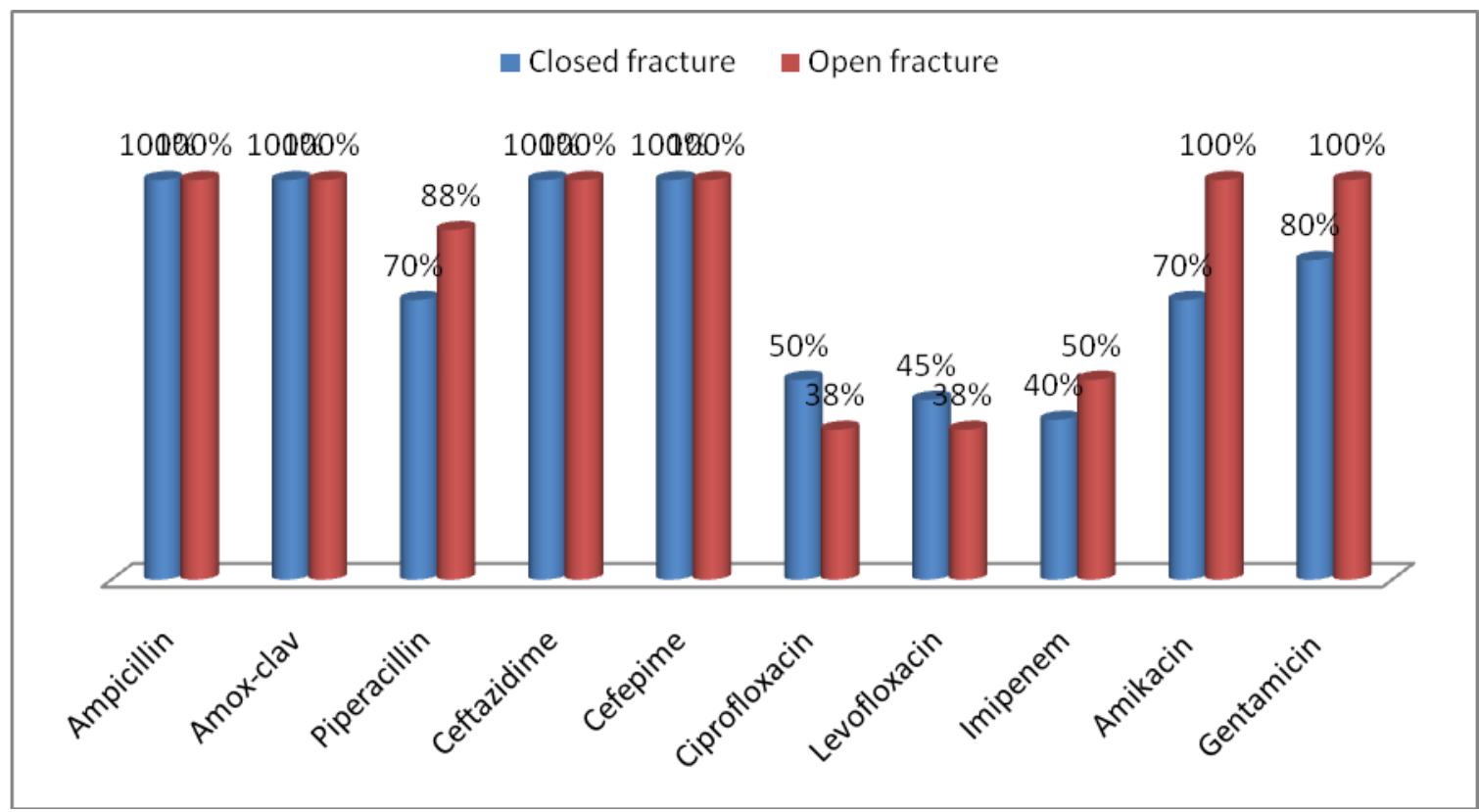

In our study there was $50 \%$ of Staphylococcus aureus were found to be MRSA in closed fracture cases and $20 \%$ in open wound fractures. Several authors have reported incidence of MRSA at different percentages. Yusof et al., 2004, noted $30 \%$ of Staph aureus to be MRSA; Lee et al., 2006 found 55\% MRSA incidence; Afifi et al., 2009 reported $50 \%$ or Staphylococcus aureus to be MRSA; Shiddanna Patted et 
al., 2013, during studies on MRSA it to be 63\% were MRSA; 9.30\% MRSA reported in national surveillance data, in England 2014. Jadranska Maksimovic et al., found that nineteen $(79.2 \%)$ of the 24 isolated Staphulococcus aureus bacteria were methicilin-resistant (MRSA).

In this study total 29 bacteria $(24.17 \%)$ out of 120 isolates were found to be ESBL producers. Of which $38.46 \%$ of E. coli, $39.13 \%$ of Enterobacter spp., $26.32 \%$ of Klebsiella, and $50 \%$ of Citrobacter spp. were ESBL producers. $38.46 \%$ isolates of Pseudomonas were also found to be ESBL producers. Similar findings were reported in study done by Hassan et al., 2010, ESBL among $21(29.2 \%)$ isolates out of 62 enterobacteriaceae isolates were found, of those isolates with percentages of $62.5 \%$ and $33.3 \%$ in Klebsiella spp. and E. coli isolates, respectively. Higher percentage of ESBL isolates were reported in study done by Joel Manyahi, 2012. ESBLs production was detected in $92.3 \%$ of Escherichia coli and $69 \%$ of Klebsiella pneumoniae.

In our study there was no significant variation of antibiotic resistance found between closed fracture and open fracture isolates.

\section{References}

Afifi, I.K., Baghagho, E.A. 2009. Three months study of orthopaedic surgical site infections in an Egyptian University hospital. Int. J. Infection Control, 1: 6(1).

Agrawal, A.C., Jain, S., Jain, R.K., Raza, H.T. 2008. Pathogenic bacteria in an orthopaedic hospital in India. $J$. Infection in Devel. Countries, 2(02): 120-3.

Akinyoola, A.L., Ako-Nai, A.K., Dosumu, O., Aboderin, A.O., Kassim, O.O.
2006. Microbial isolates in early swabs of open musculoskeletal injuries. The Nigerian Postgrad. Med. J., 13(3): 176-81.

Ako-Nai, A.K., Ikem, I.C., Daniel, F.V., Ojo, D.O., Oginni, L.M. 2009. A comparison of superficial and deep bacterial presence in open fractures of the lower extremities. The Int. J. Lower extremity wounds, (4): 197-202. Al-Mulhim, F.A., Baragbah, M.A., SadatAli, M., Alomran, A.S., Azam, M.Q. 2014. Prevalence of surgical site infection in orthopedic surgery: a 5year analysis. Int. surgery, 99(3): 2648.

Anderson, D.J., \& Sexton, D.J. 2007. Epidemiology and pathogenesis of and risk factors for surgical site infection.

Badoe, E., Archampong, E., Jaja, M. 1986. Principles and practice of surgery including pathology in the tropics. Tema, Ghana: Ghana Pub. Corp.

Bauer, A.W., Kirby, W.M,. Sherris, J.C., Turck, M. 1966. Antibiotic susceptibility testing by a standard single disc method. Am. J. Clin. Pathol., 45: 493-6.

Clinical and Laboratory Standards Institute (CLSI). Performance standards for antimicrobial susceptibility testing. $25^{\text {th }}$ informational supplement: 2015.p. M100-S25.

Davies, J., Davies, D. 2010. Origins and evolution of antibiotic resistance. Microbiol. Mol. Biol. Rev., 1;74(3): 417-33.

De Bakey, M.E, Simeone, F.A. 1946. Battle injuries of the arteries in world war II: an analysis of 2471 cases. Ann. Surg., 123: 534-579.

Faisham, W.I., Nordin, S., Aidura, M. 2001. Bacteriological study and its role in the management of open tibial fracture. The Medical J. Malaysia, 56(2): 201-6. 
Fischer, M.D., Gustillo, R.B., Varecka, T.F. 2000. The timing of flap coverage, bone grafting and intramedullary nails inserted with and without reaming for the treatment of open and closed fractures of tibial shaft. J. Orthop. Trauma, 14: 187-193.

Hassan, A.M., Ibrahim, O., El Guinaidy, M. 2010. Surveillance of antibiotic use and resistance in orthopaedic department in an Egyptian university hospital. Int. J. Infect. Control, 15: 7(1).

Hidron, A.I., Edwards, J.R., Patel, J., Horan, T.C., Sievert, D.M., Pollock, D.A., Fridkin, S.K. 2008. Antimicrobialresistant pathogens associated with healthcare-associated infections: annual summary of data reported to the National Healthcare Safety Network at the Centers for Disease Control and Prevention, 2006-2007. Infection Control \& Hospital Epidemiol., 29(11): 996-1011.

Horan, T.C., Gaynes, R.P., Martone, W.J., Jarvis, W.R., Emori, T.G. 1992. CDC definitions of nosocomial surgical site infections. A modification of CDC definitions of surgical wound infections. Infect. Control Hosp. Epidemiol., 3(10): 606-608.

Jain, R.K., Shukla, R., Singh, P., Kumar, R. 2015. Epidemiology and risk factors for surgical site infections in patients requiring orthopaedic surgery.

European J. Orthopaedic Surgery \& Traumatol., 25(2): 251-4.

Khairy, G.A., Kambal, A.M., Al-Dohayan, A.A., Al-Shehri, M.Y., Zubaidi, A.M., Al-Naami, M.Y., AlSaif, F.A., AlObaid, O.A., Al-Saif, A.A., El-Farouk, O.Y., Al-Abdulkarim, A.A. 2011. Surgical site infection in a teaching hospital: a prospective study. $J$. Taibah University Med. Sci., 6(2): 114-20.
Kirk, R.M., Ribbans, W.J. 2004. Clinical surgery in general (RCS course manual), $4^{\text {th }}$ ed. Churchill livingstone, London, UK; 206-382.

Lee, J., Singletary, R., Schmader, K., Anderson, D.J., Bolognesi, M., Kaye, K.S. 2006. Surgical site infection in the elderly following orthopaedic surgery. J. Bone Joint Surg. Am., 88(8): 1705-12.

Li, G.Q., Guo, .F.F, Ou, Y., Dong, G.W., Zhou, W. 2013. Epidemiology and outcomes of surgical site infections following orthopedic surgery. American J. Infection Control, 41(12): 1268-71.

Lilani, S.P., Jangale, N., Chowdhary, A., Daver, G.B. 2005. Surgical site infection in clean and cleancontaminated cases. Indian J. Med. Microbiol., 23(4): 249.

Madu, K.A., Enweani, U.N., Katchy, A.U., Madu, A.J., Aguwa, E.N. 2010. Implant associated surgical site infection in orthopaedics: a regional hospital experience. Nigerian journal of medicine: J. National Association of Resident Doctors of Nigeria, 20(4): 435-40.

Malepo, P. 2014. Antimicrobial susceptibility patterns of bacteria isolated from open fracture infections at Mulago Hospital (Doctoral dissertation, Makerere University).

Mangram, A.J., Horan, T.C., Pearson, M.L., Silver, L.C., Jarvis, W.R. 1999. Guideline for Prevention of Surgical Site Infection, 1999. Centers for Disease Control and Prevention (CDC) Hospital Infection Control Practices Advisory Committee. Am. J. Infect. Control, 27: 97-132.

Ochsner, P.E. 1992. Prognosis and complications of open fractures. Helv. Chir. Acta, 59: 129-141. 
Onche, I., Adedeji, O. 2006. Microbiology of post-operative wound infection in implant surgery. Nigerian J. surgical Res., 6(1-2).

Patzakis, M.J., Wilkins, J. 1989. Factors influencing infection rate in open fracture wounds. Clin. Orthop., 243: 36-40.

Rajkumari, N., Gupta, A.K., Mathur, P., Trikha, V., Sharma, V., Farooque, K., Misra, M.C. 2014. Outcomes of surgical site infections in orthopedic trauma surgeries in a tertiary care centre in India. J. Postgrad. Med., 60(3): 254.

Rastogi, V., Mishra, P.K., Bhatia, S. 2014. Emerging antimicrobial resistance in hospital a threat to public health. Ind. J. Comm. Health, 24(4): 260-263.

Robinson, D., On, E., Hadas, N., Halperin, N., Hofman, S., Boldur, I. 1989. Microbiologic flora contaminating open fractures: its significance in the choice of primary antibiotic agents and the likelihood of deep wound infection. J. Orthop. Trauma, 3: 2836.

Shija, J.K. 1976. The Incidence and Pattern of Sepsis Among General Surgical InPatients at Muhimbili Hospital, Dar Es Salaam, 1973- A Preliminary Report. East African Med. J., 53(3): 153-159.

Sule, A.M., Thanni, L., Sule Odu, A.O., Olusanya, O. 2002. Bacterial pathogens associated with infected wounds in Ogun State University Teaching Hospital, Sagamu, Nigeria. Af. J. Clin. Experimental Microbiol., 3: 13-16.

Wang, H.Y., Duan, X., Chen, Y., Li, J. 2009. [Microbiologic study on the pathogens isolated from wound culture among orthopaedic patients after Wenchuan earthquake]. Zhongguo gu shang= China J. Orthopaedics And Traumatol., 22(12): 910-2.

Yusof, M.I., Yusof, A.H. 2004. Orthopaedic infections: organisms and antibiotic sensitivity. The Med. J. Malaysia, 59(5): 574-7.

\section{How to cite this article:}

Vinod Maurya, Prabhat Kiran Khatri, R.S. Parihar, Kishor Raichandani, Saroj Meena, Archana Bora, Laxmi Rathore, Shivani Khullar, K.L. Seervi and Kamlesh Kumar. 2016. Incidence of Aerobic Bacterial Infection in Postoperative Closed and Open Fracture Wounds at Tertiary Care Hospital in Western Rajasthan, India. Int.J.Curr.Microbiol.App.Sci. 5(12): 475-485. doi: http://dx.doi.org/10.20546/ijcmas.2016.512.051 